\title{
A Promising Tool for Subsurface Permafrost Mapping: An Application of Airborne Geophysics from the Yukon River Basin, Alaska
}

Permafrost is a predominant physical feature of the Earth's Arctic and Subarctic clines and a major consideration encompassing ecosystem structure to infrastructure engineering and placement. Perennially frozen ground is estimated to cover about 85 percent of the state of Alaska where northern reaches are underlain with continuous permafrost and parts of interior Alaska are underlain by areas of discontinuous and (or) sporadic permafrost (fig. 1). The region of Interior Alaska, where permafrost is scattered among unfrozen ground, is a complex mosaic of terrains and habitats. Such diversity creates arrays of lakes and surface-water and groundwater patterns that continental populations of migratory waterfowl and internationally significant fisheries have adapted to over time. A road or pipeline might pass over frozen and unfrozen ground, affecting the types of materials and engineering approaches needed to sustain the infrastructure.

Effective mapping of discontinuous permafrost at scales meaningful ecologically and (or) from an engineering perspective has been a long-standing challenge. Using techniques such as borehole logging for site-specific assessments or botanical techniques that can suggest underlying permafrost distributions can be labor intensive and difficult to accomplish at the scale and remoteness of much of Alaska.

The climate is changing in the Arctic and Subarctic regions. The warming observed throughout much of Alaska could create widespread changes in permafrost. How the warming of the permafrost affects near-surface processes, ecosystems, and community infrastructure and ecosystems is not clear. A better understanding of the dynamic distribution and physical properties of permafrost, from continuous to discontinuous, will provide knowledge of how the permafrost environment may change in the future and help inform engineering and natural resource response strategies.

Here we discuss an application of an airborne remote sensing methodology for mapping and shade imaging permafrost characteristics at various scales. This work provides the first look into three-dimensional distribution of permafrost in the areas around Fort Yukon and is a demonstration of the application of airborne electromagnetic (AEM) to permafrost mapping. Such an approach is attractive, particularly in Arctic and Subarctic studies, where ground access is difficult and ecosystems arefragile.

In June 2010, the U.S. Geological Survey (USGS) conducted an AEM survey near Fort Yukon, Alaska. The primary focus of this survey was to map the distribution of permafrost in selected areas in order to supply information for the development of groundwater models of the Yukon River Basin. However,

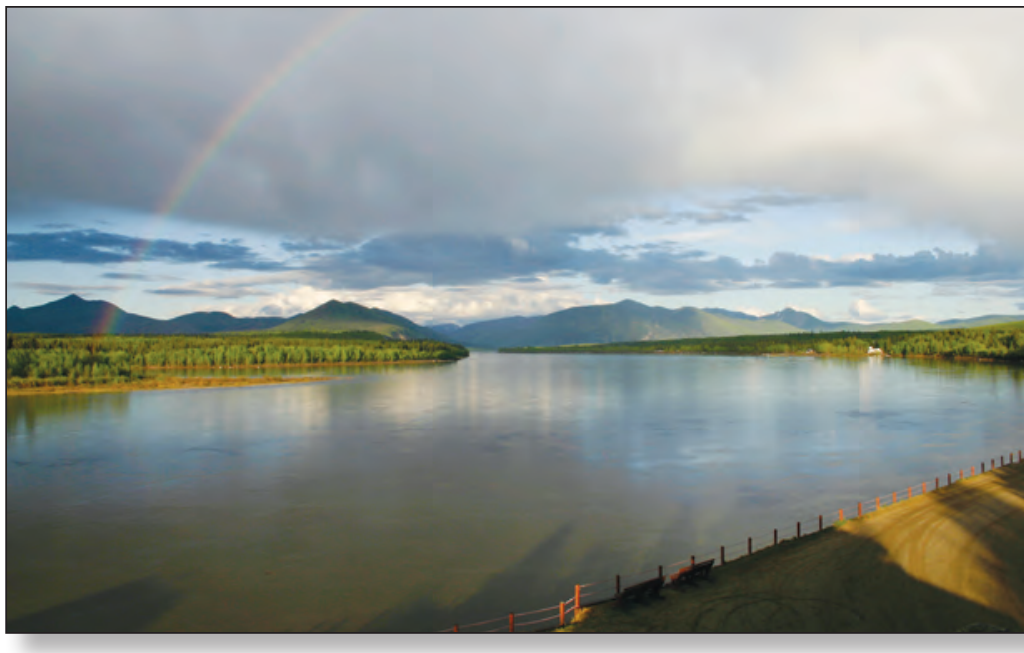

Yukon River at Eagle, Alaska.

the methodologies have more far-reaching ecological and engineering applications. Approximately 1,800 line kilometers were acquired in a combination of typical block style surveying in the immediate area of Fort Yukon and in long reconnaissance lines over a broader area. The widely spaced lines were flown to cross the modern Yukon River in "X" like patterns with intersections at features that have been previously studied (fig. 2).

AEM is used to gather data on the electrical resistivity of materials in the subsurface below the flight path of the helicopter, which are then analyzed to interpret the subsurface lithology and the location and extent of permafrost. For this survey, the electrical resistivity was imaged to depths on the order of 50-100 meters. Images from the survey can be qualitatively compared with known permafrost features and suggest new permafrost features. Electrical properties of earth materials are affected by lithology as well as temperature and the presence of ice; frozen materials become substantially more resistive. This allows for the identification of permafrost from the resistivity image (Abraham and others, 2011).

In the area of Fort Yukon, the AEM survey shows elevated resistivities extending to depth, likely indicative of thick permafrost. This depth corresponds well to observations from a borehole drilled in the area in the late 1990s, which detected permafrost to a depth of about 100 meters (Clark and others, 2009). In contrast to the area of Fort Yukon, the Yukon River and its floodplain are not associated with deep resistive sediments, suggesting a lack of deep permafrost, at least within the depth range of the AEM mapping (fig. 3). 


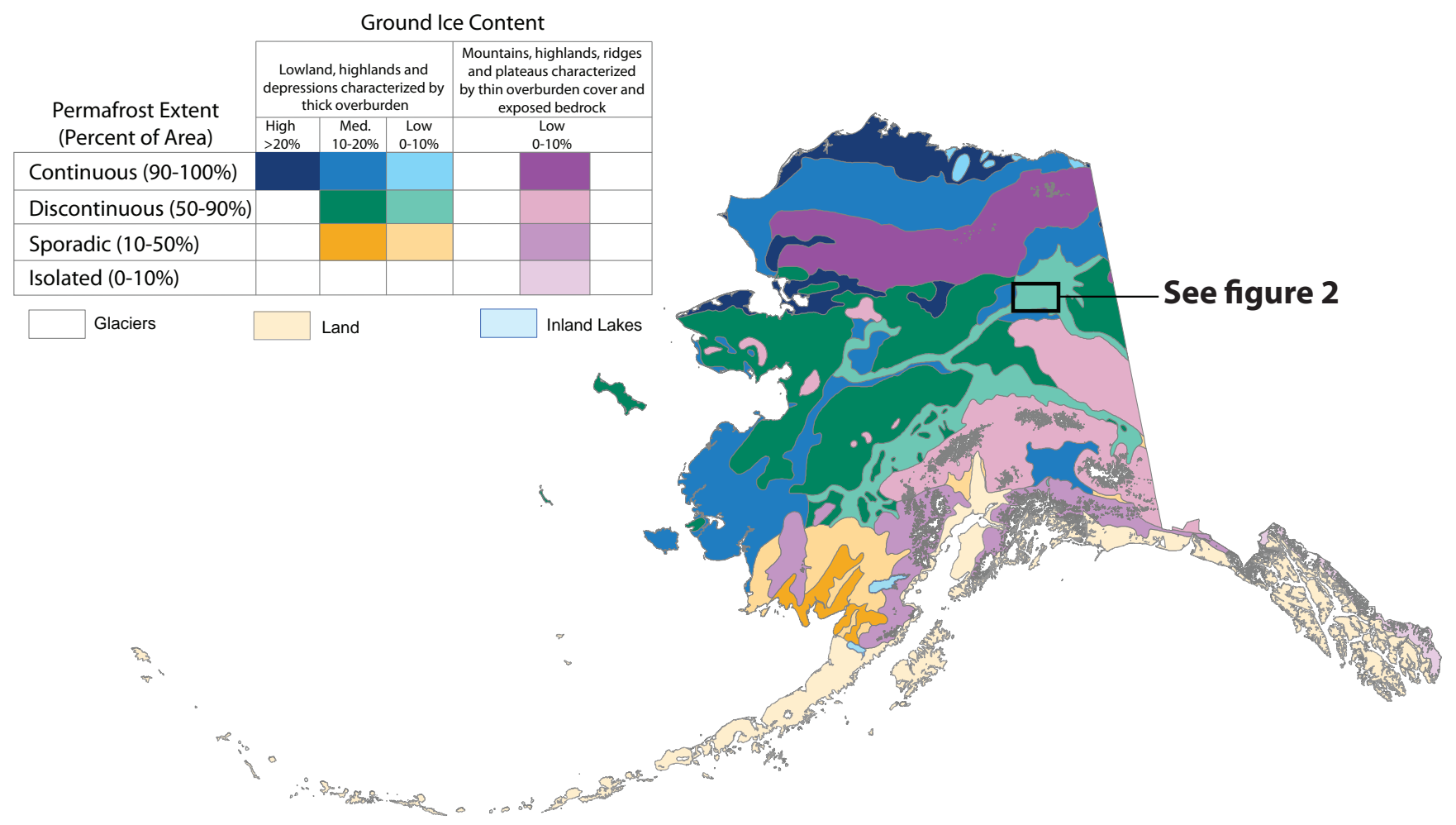

Figure 1. Map of the permafrost extent in Alaska (Brown and others, 1998). Box indicates location of geophysical survey within the discontinuous permafrost area.

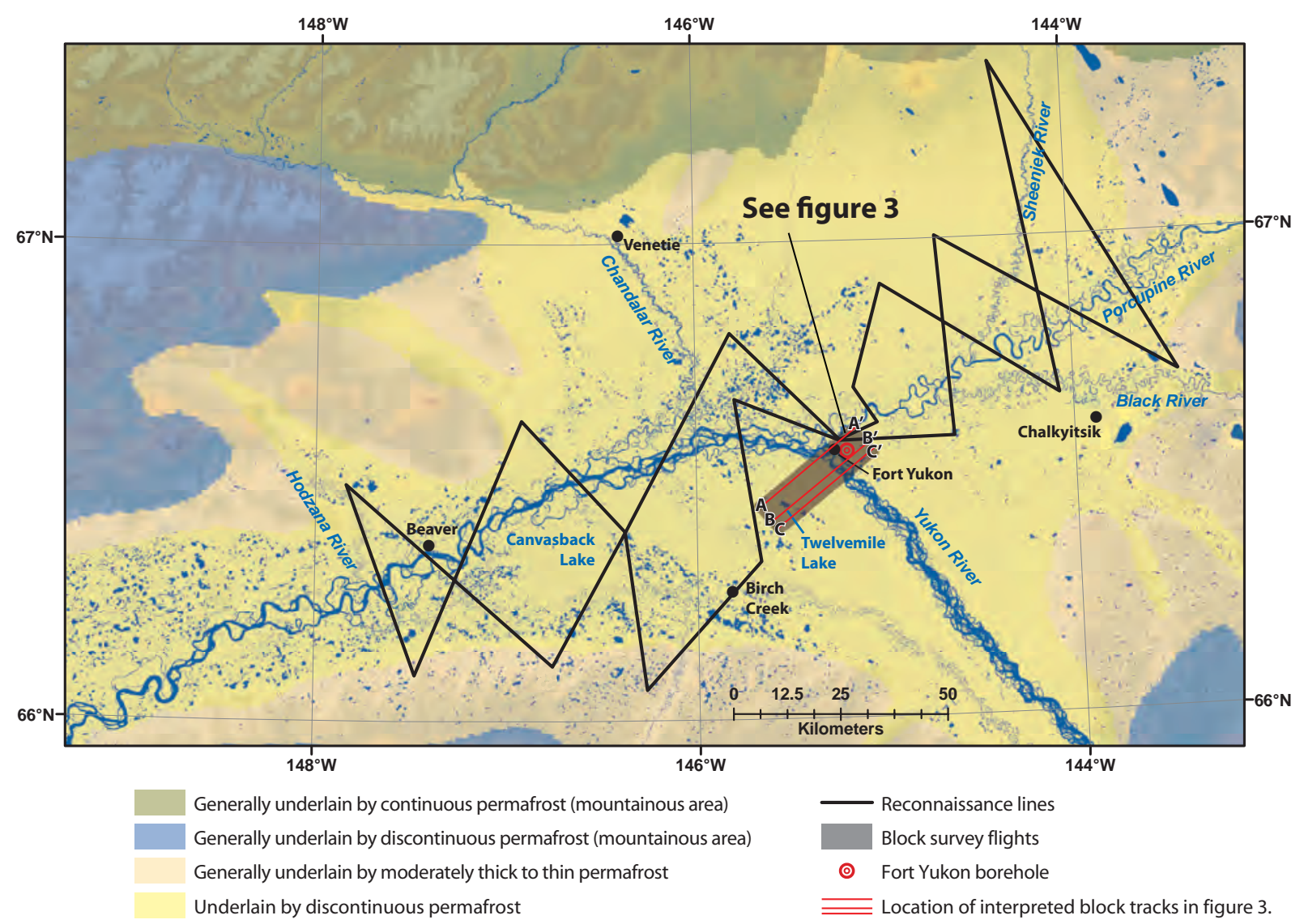

Figure 2. Geophysical study area with surface-water features and permafrost characteristics, Yukon River basin, Alaska (Ferrians, 1965). Standard block flights and reconnaissance flight lines were collected. Resistivity cross sections shown in figure 3. 


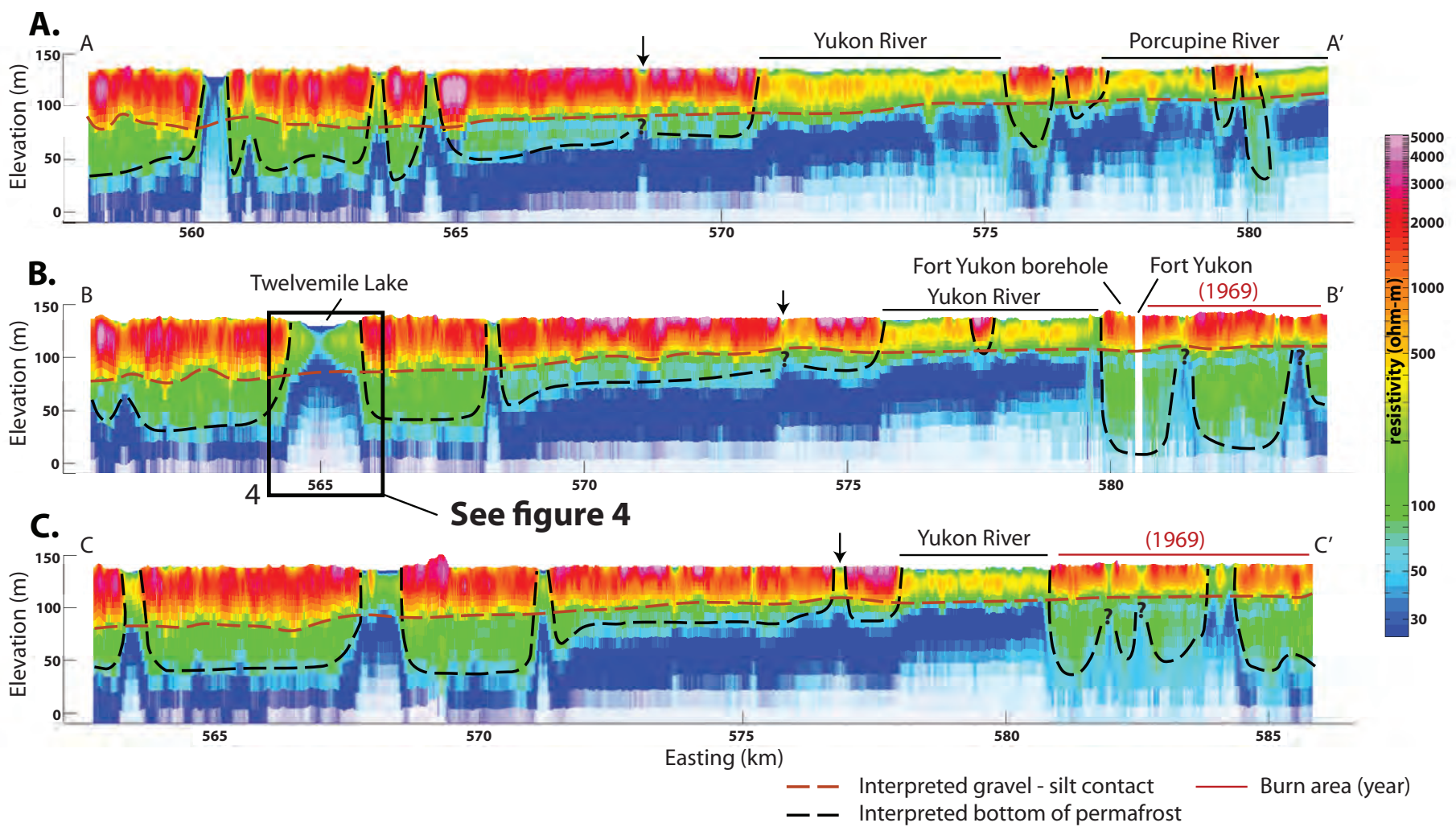

Figure 3. Resistivity cross sections along the three transects with relevant surface features and recent burn areas. The downward-pointing arrows indicate the location of a sinuous side channel of the Yukon River that also is evident as a shallow low-resistivity zone. Interpreted lithologic and permafrost boundaries are superimposed as dashed lines. Vertical exaggeration is approximately 25:1. Locations of cross sections are shown in figure 2.

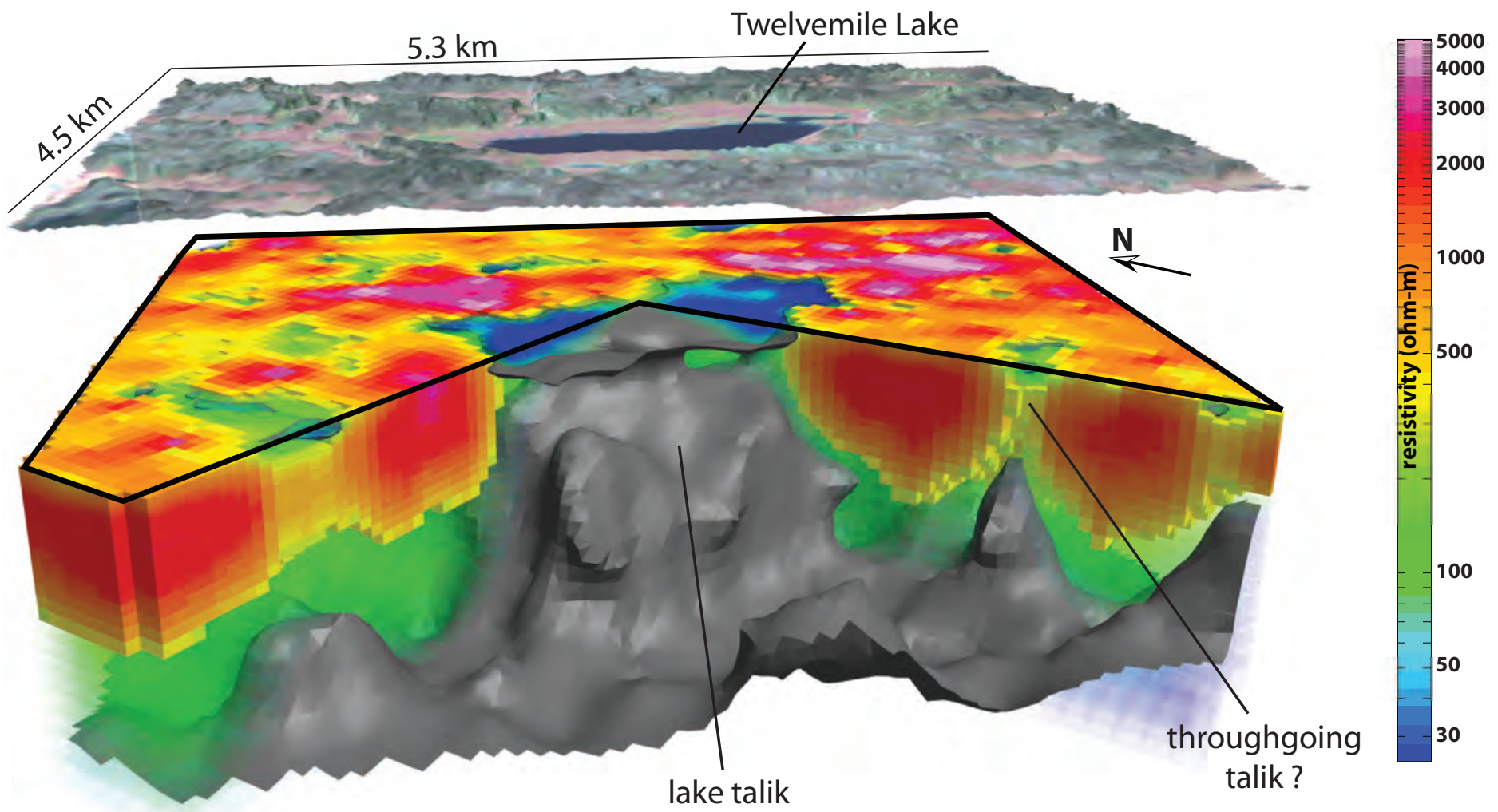

Figure 4. Three-dimensional cutout view showing the resistivity model near Twelvemile Lake, Alaska. The grey isosurface is the interpreted base of permafrost in the subsurface. The upper image is a Landsat view of the region displayed below. Vertical exaggeration is 12:1. 
From this survey, we can examine unfrozen features, such as taliks, that occur within the permafrost region and that may play an important role in groundwater flow. One such feature mapped in the survey is the talik associated with Twelvemile Lake. A 3-D model interpretation was developed of the talik below Twelvemile Lake as well as other thawed subsurface features. It is not yet certain whether these features are fully connected (fig. 4).

Interpretations of the AEM data are being integrated with other remotely sensed data to supply critical hydrogeological information needed for improving the understanding of groundwater-surface-water interactions in permafrost terrains. This information is being directly used for refining groundwater flow models in the Yukon Flats Basin. The AEM interpretations are also providing baseline data for estimating the 3-D distribution of permafrost, which can be compared to future permafrost surveys to assess changes over time. Through improved ability to identify permafrost characteristics, we can start to identify and detect changes and trends through time. This will help with management of infrastructure and knowledge of ecosystems as permafrost changes in response to a warming climate.

The research was funded by the U.S. Geological Survey's Climate Effects Network Project, and the U.S Geological Survey Mineral Resources Program's Integrated Methodology Project.

\section{Airborne Electromagnetic Systems (AEM)}

From an airborne platform, AEM systems transmit an electromagnetic signal that induces electrical currents in the earth, which are subsequently sensed by receiver coils in the system.

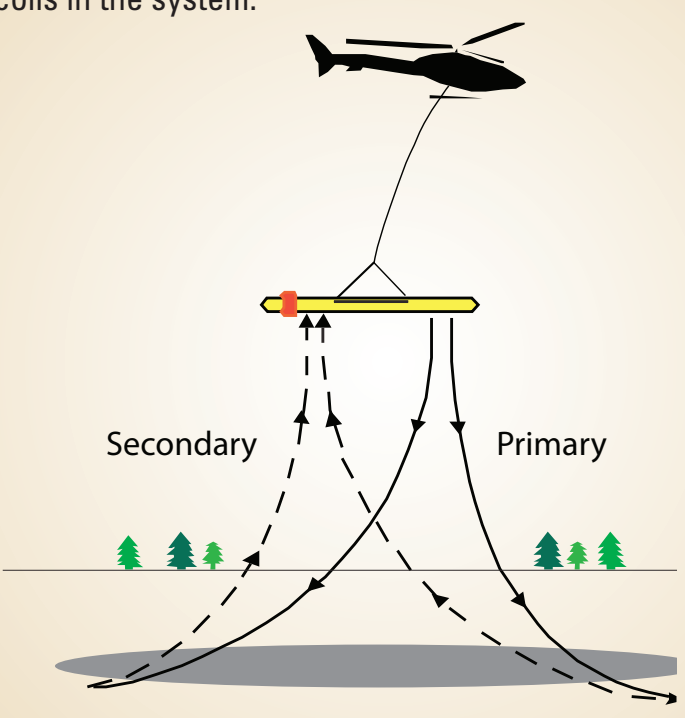

The signal received by the coils changes with the type of subsurface material and amount of ice present beneath the system. This information then can be analyzed to predict the lithology of the subsurface material and determine the extent of permafrost.

\section{Opportunities for Future Work}

The AEM surveys over permafrost terrains can be used:

- To plan infrastructure projects such as road, pipeline, and energy/mineral development.

- As a basis for extrapolation of permafrost using other regional information (remote sensed data).

- To understand the important effect of permafrost on ecological processes (groundwater-surface-water interactions).

- To understand thawing processes.

- To provide a base line for future monitoring.

\section{References Cited}

Abraham, J.D., Ball, L.B., Cannia, J.C., Jorgenson, T., Minsley, B.J., Smith, B.D., Walvoord, M.A., Wylie, B.K., and Voss, C.I., 2011, Airborne electromagnetic mapping of subsurface permafrost-Quantifiable characterization for now and in the future [abs.]: 6th International Conference on Arctic Margins, Fairbanks, Alaska, May 30-June 3, 2011.

Brown, J., Ferrians, O.J., Heginbottom, J.A., and Melnikov, E.S., 1998, [revised February 2001], Circum-Arctic map of permafrost and ground ice conditions: Boulder, Colo., National Snow and Ice Data Center/World Data Center for Glaciology, digital media, accessed June 29, 2011, at http:// nsidc.org/data/docs/fgde/ggd318_map_circumarctic/index. $\underline{\mathrm{html}}$.

Clark, Arthur, Barker, C.E., and Weeks, E.P. 2009, Drilling and testing the DOI-04-1A coalbed methane well, Fort Yukon, Alaska: U.S. Geological Survey Open-File Report 2009$1064,69 \mathrm{p}$

Ferrians, O.J., 1965, Permafrost map of Alaska, USA: Boulder, Colo., National Snow and Ice Data Center/World Data Center for Glaciology, digital media, accessed July 25, 2011, at http://nsidc.org/data/ggd320.html.

\section{Author: Jared Abraham jdabraha@usgs.gov}

\section{For Information Contact:}
Regional Executive for Alaska
U.S. Geological Survey
4210 University Dr.
Anchorage, AK 99508
http://alaska.usgs.gov
907-786-7000

Photograph credit: Yukon River at Eagle, AlaskaDaniel Long, U.S. Geological Survey.

Publishing support provided by the

U.S. Geological Survey

Tacoma Publishing Service Center 